\title{
Impact of short-term exposure to fine particulate matter on emergency ambulance dispatches in Japan
}

\author{
Takehiro Michikawa, ${ }^{1}$ Kayo Ueda, ${ }^{1}$ Ayano Takeuchi, ${ }^{1}$ Makoto Kinoshita, ${ }^{2}$ \\ Hiromi Hayashi, ${ }^{2}$ Takamichi Ichinose, ${ }^{3}$ Hiroshi Nitta ${ }^{1}$
}

\begin{abstract}
- Additional material is published online only. To view please visit the journal online (http://dx.doi.org/10.1136/jech2014-203961).

${ }^{1}$ Environmental Epidemiology Section, Center for

Environmental Health Sciences, National Institute for Environmental Studies, Tsukuba, Japan

${ }^{2}$ Environmental Bureau of

Fukuoka City, Fukuoka, Japan ${ }^{3}$ Department of Health Sciences, Oita University of Nursing and Health Sciences, Oita, Japan
\end{abstract}

\section{Correspondence to} Dr Takehiro Michikawa, Environmental Epidemiology Section, Center for Environmental Health Sciences, National Institute for Environmental Studies, Onogawa 16-2, Tsukuba, Ibaraki 305-8506, Japan; tmichikawa@nies.go.jp

Received 4 February 2014 Revised 11 August 2014 Accepted 4 September 2014 Published Online First 18 September 2014

\section{ABSTRACT}

Background Evidence of an association between fine particulate matter $\left(\mathrm{PM}_{2.5}\right)$ and morbidity is limited in Asia. We used a case-crossover design to evaluate the association between short-term exposure to $\mathrm{PM}_{2.5}$ and emergency ambulance dispatches (as a proxy of acute health outcomes), and to calculate the extent to which a $10 \mu \mathrm{g} / \mathrm{m}^{3}$ decrease in $\mathrm{PM}_{2.5}$ concentrations would reduce the number of ambulance dispatches.

Methods We used data on emergency ambulance dispatches in Fukuoka City, Japan between 2005 and 2010. Emergency ambulance services are publicly funded and cover the entire city. After excluding ambulance dispatches related to external injuries and pregnancy/ childbirth, we analysed data on the remaining 176123 dispatches. We also collected records of daily concentrations of $\mathrm{PM}_{2.5}$ from one ambient air pollution monitoring station. ORs per $10 \mu \mathrm{g} / \mathrm{m}^{3}$ increase in $\mathrm{PM}_{2.5}$ were estimated using conditional logistic regression controlled for ambient temperature and relative humidity. Results During the study period, the average daily concentration of $\mathrm{PM}_{2.5}$ was $20.3 \mu \mathrm{g} / \mathrm{m}^{3}$. Exposure to $\mathrm{PM}_{2.5}$ was associated with emergency ambulance dispatches in general (lag0-1; OR=1.008 $(95 \% \mathrm{Cl}$ 1.002 to 1.014$)$ ) and with dispatches due to respiratory diseases (lag0-1; OR=1.027 (1.007 to 1.048)). No association was observed for dispatches due to cardiovascular diseases. We estimated that a $10 \mu \mathrm{g} / \mathrm{m}^{3}$ decrease in $\mathrm{PM}_{2.5}$ concentrations would have led to approximately 260 (estimated range $=70-460$ ) fewer ambulance dispatches in Fukuoka for 2012.

Conclusions Providing further evidence on the shortterm health effects of $\mathrm{PM}_{2.5}$ exposure, we found that exposure was associated with an increased number of emergency ambulance dispatches. The effect was, however, relatively small.

\section{INTRODUCTION}

There is growing evidence that exposure to particulate matter harms human health, ${ }^{1}$ even though the effects may seem relatively small in comparison with those of major risk factors like smoking. However, as more and more populations are exposed to particulate matter, it is becoming a global public health burden. A systematic analysis for the Global Burden of Disease Study 2010 put fine particulate matter $\left(\mathrm{PM}_{2.5}\right.$, ie, fine particulate matter collected with a sampler with a 50\% cut-off point of $2.5 \mu \mathrm{m}$ ) in the top 10 causes of disease burden worldwide, accounting for 3.2 million deaths in $2010 .^{2}$
There is limited evidence on the health effects of $\mathrm{PM}_{2.5}$ exposure in Japan, because air quality standards were based on suspended particulate matter measurements (particles with diameters of less than $10 \mu \mathrm{m})$ until $\mathrm{PM}_{2.5}$ was added as a criterion in 2009. In other Asia countries, evidence of an association between exposure to $\mathrm{PM}_{2.5}$ and morbidity is also more limited than it is in Europe and the USA. It is also clear from the literature that epidemiological evidence collected in Western countries cannot necessarily be extrapolated to Asian populations. In addition, the health effects of $\mathrm{PM}_{2.5}$ have been reported to differ according to its chemical composition, which is affected by geographic location. ${ }^{3}$ Therefore, the health effects of $\mathrm{PM}_{2.5}$ exposure needs further study in Asia. In Japan, this association has become a matter of national concern because of high concentrations found in air pollution drifting periodically into the country from other East Asian nations recently. ${ }^{4}$ Information on the short-term health effects of $\mathrm{PM}_{2.5}$ that are closely connected to everyday life is urgently needed.

The purpose of the present time-stratified casecrossover study was to examine whether short-term increases in $\mathrm{PM}_{2.5}$ concentrations are associated with the number of emergency ambulance dispatches in Japan. There is precedent for using ambulance dispatch data to examine the health effects of $\mathrm{PM}_{2.5^{6}}{ }^{7}$; such data are helpful in assessing acute health events related to respiratory and cardiovascular diseases, which are the main focus of epidemiological studies on $\mathrm{PM}_{2.5}$. Quantification of the public health impact of $\mathrm{PM}_{2.5}$ exposure is important, so we also calculated the extent to which a $10 \mu \mathrm{g} / \mathrm{m}^{3}$ decrease in $\mathrm{PM}_{2.5}$ concentrations would reduce the number of ambulance dispatches.

\section{MATERIALS AND METHODS \\ Study area}

This study was carried out in Fukuoka City, Fukuoka Prefecture, one of the biggest cities in Japan (see online supplementary figure), with a population of approximately 1.5 million, and a moderate climate (average annual temperature c. $\left.17^{\circ} \mathrm{C}\right)$. Fukuoka is in Kyushu $\left(130^{\circ} 24^{\prime} \mathrm{E}, 33^{\circ}\right.$ $35^{\prime} \mathrm{N}$ ), the closest of Japan's main islands to the Asian continent, making it susceptible to transboundary air pollution. ${ }^{48}$ Owing partly to this susceptibility, $\mathrm{PM}_{2.5}$ concentrations in Fukuoka are relatively high compared with other Japanese cities; the range of daily mean concentrations is also wide. $^{9}$
To cite: Michikawa T,
Ueda K, Takeuchi A, et al. J

Epidemiol Community Health 2015;69:86-91. 


\section{Environmental data}

We obtained data on $\mathrm{PM}_{2.5}$ from Fukuoka City. The tapered element oscillating microbalance (TEOM) method was used to measure hourly concentrations of $\mathrm{PM}_{2.5}$ almost every day during the 2191-day study period (measurements were unavailable for $1.3 \%$ of the total days) at one ambient air pollution monitoring station selected as representative of the urban background in Fukuoka, and daily mean concentrations were calculated. TEOM measurements correlate well with those obtained by the federal reference method. ${ }^{10}$

Data on other pollutants (nitrogen dioxide $\left(\mathrm{NO}_{2}\right)$, photochemical oxidants $(\mathrm{Ox})$ and sulfur dioxide $\left(\mathrm{SO}_{2}\right)$ ) were obtained from the National Institute for Environmental Studies' atmospheric environment database. $\mathrm{Ox}$ is defined as mixtures of ozone and other secondary oxidants generated by photochemical reactions, and is considered to be a proxy for ozone. Hourly data from eight monitoring stations in Fukuoka were collected, and daily mean concentrations of $\mathrm{NO}_{2}$ and $\mathrm{SO}_{2}$ were calculated across the monitoring stations, along with average daily maximum $8 \mathrm{~h}$ mean concentrations of $\mathrm{Ox}$.

Meteorological data were obtained from the Japan Meteorological Agency. Hourly measurements were used to calculate daily mean ambient temperatures and relative humidity. Data on weekly influenza incidence were obtained from the Japan National Institute of Infectious Diseases. Influenza epidemic week was defined as the week when the weekly number of influenza cases was above the 90th centile of distribution during the study period or not, ${ }^{11}$ so influenza was a dichotomised variable as epidemic week or not.

\section{Information on emergency ambulance dispatches}

In Japan, emergency medical services are provided free of charge by local governmental fire defence headquarters, ${ }^{12} 13$ and citizens can call ambulances via the emergency number 119 .

We obtained data on 307711 emergency ambulance dispatches covering the entire city of Fukuoka between 1 January 2005 and 31 December 2010. After excluding dispatches related to external injuries and pregnancy/childbirth, we were left with data on 176123 dispatches (57.2\%) for analysis. Records of the initial diagnoses made at the emergency departments where the transported patients were treated were used to code the causes of the ambulance dispatches according to the International Classification of Diseases, 10th revision (ICD-10); one medical doctor (TM) did the coding. Since there is evidence of an association between $\mathrm{PM}_{2.5}$ and cardiopulmonary diseases, ${ }^{1}$ we defined ambulance dispatches related to respiratory diseases (ICD-10: J00-99) and cardiovascular diseases (ICD-10: I00-99), which accounted for $9 \%(n=15857)$ and $18.1 \%(n=31837)$ of the total, respectively, as cause-specific. The ratio of ambulance dispatches due to respiratory and cardiovascular diseases was similar to that found in an earlier study in another Japanese city. ${ }^{14}$

We submitted the study protocol to the Ethical Review Board of the National Institute for Environmental Studies for approval but were told by the Board that approval was not required because the study data did not include individual identifiers.

\section{Statistical analyses}

The case-crossover design used in this study was developed to assess the acute effects of transient exposure. The design has the ability to control for time-invariant characteristics such as age and sex, because within-subject comparisons are made between case periods and control periods. Case periods in this study were defined as the days of emergency ambulance dispatches, and the control periods (3-4 per case) were selected on corresponding days of the week within the same calendar month. For example, if an ambulance was dispatched on 15 October, four control days were assigned: 1, 8, 22 and 29 October. This control selection strategy is called 'time-stratification', and is designed to adjust for time-dependent confounding within strata-time by methods. ${ }^{15}$

Conditional logistic regression models were used to estimate the adjusted ORs and 95\% CIs of emergency ambulance dispatches associated with $10 \mu \mathrm{g} / \mathrm{m}^{3}$ increases in $\mathrm{PM}_{2.5}$ concentrations, after including the mean ambient temperature (a natural spline with $4^{\circ}$ of freedom) and relative humidity from the case day (lag0) to 3 days prior (lag3). To evaluate the lag effect of $\mathrm{PM}_{2.5}$, we applied a lag-stratified distributed lag model, ${ }^{16}$ entering the average concentrations of $\mathrm{PM}_{2.5}$ during the case day $(\operatorname{lag} 0)$ to 1 day preceding it ( $\operatorname{lag} 1)(\operatorname{lag} 0-1)$, during lag2-lag3 (lag2-3) and during lag4-lag6 (lag4-6) simultaneously. To confirm the robustness of $\mathrm{PM}_{2.5}$ effect estimates against potential confounding by $\mathrm{NO}_{2}, \mathrm{Ox}$ and $\mathrm{SO}_{2}$, we constructed twopollutant models adjusted for the mean concentrations of each copollutant (lag0-3). Pearson's correlations coefficients between $\mathrm{PM}_{2.5}$ and the other pollutants were 0.43 for $\mathrm{NO}_{2}, 0.41$ for $\mathrm{Ox}$ and 0.60 for $\mathrm{SO}_{2}$ (see online supplementary table S1). Although these correlations by season were different, particularly regarding $\mathrm{Ox}$, there was no statistical evidence in two-pollutant models that the association between $\mathrm{PM}_{2.5}$ and ambulance dispatches varied according to season. We also performed stratified analyses by age (0-19 years, 20-64 years and 65 years or older) and sex to examine the effects by subgroup, and a statistical check for interaction by age strata and sex using the likelihood ratio test. Similar analyses were repeated to investigate other pollutants. Furthermore, several sensitivity analyses were performed. First, because of possible bias in control selection, we excluded participants transported to hospitals on national holidays. Second, we investigated whether any association between $\mathrm{PM}_{2.5}$ and ambulance dispatches was detectable when $\mathrm{PM}_{2.5}$ concentrations were lower than those of air quality standards stipulated by the Japanese Ministry of the Environment ${ }^{17}$ and US Environmental Protection Agency ${ }^{18}$ (daily mean, $35 \mu \mathrm{g} / \mathrm{m}^{3}$ ), and by the $\mathrm{WHO}^{19}$ (daily mean, $25 \mu \mathrm{g} / \mathrm{m}^{3}$ ): analyses were restricted to participants exposed to $\mathrm{PM}_{2.5}$ concentrations below those values. Third, we additionally adjusted for influenza epidemics. And fourth, to check for possible confounding by the effects of prolonged low temperatures, a significant factor in respiratory disease, ${ }^{20}$ we adjusted for temperature at lag0-14. ${ }^{11}$

To illustrate the public health impact, we estimated the reduction in the number of annual emergency ambulance dispatches attributable to a $10 \mu \mathrm{g} / \mathrm{m}^{3}$ decrease in the daily $\mathrm{PM}_{2.5}$ concentrations. In accordance with a modified method for calculating the population attributable fraction, ${ }^{21}$ the annual reduction was defined as $\mathrm{N} \times(\mathrm{OR}-1) / \mathrm{OR}$, where $\mathrm{N}$ was the number of annual ambulance dispatches excluding those related to external injuries and pregnancy/childbirth. By multiplying the total number of ambulance dispatches by $0.572(57.2 \%)$, we thus assumed approximately 33000 ambulance dispatches in Fukuoka for $2012^{22}$ as N. We also estimated the corresponding reduction in administrative expenditure based on a rate of 7600 Japanese yen per ambulance dispatch $^{23}$ and using exchange rates of 100 yen $=\$ 1=€ 0.7$.

All statistical analyses were performed with Stata V.11 (Stata Corporation, College Station, Texas, USA), and statistical tests were two-tailed with significance levels set at $\mathrm{p}<0.05$.

\section{RESULTS}

Of the 176123 emergency ambulance dispatches investigated, $9.3 \%$ were for persons aged $0-19$ years, $45.3 \%$ for people aged 
Table 1 Summary of meteorological factors and daily mean concentrations of air pollutants from January 2005 to December 2010 in Fukuoka, Japan

\begin{tabular}{|c|c|c|c|c|c|c|c|}
\hline \multirow[b]{2}{*}{ Pollutants } & \multirow[b]{2}{*}{ Number of days } & \multirow[b]{2}{*}{ Mean (SD) } & \multirow[b]{2}{*}{ Min } & \multirow[b]{2}{*}{ IQR } & \multirow[b]{2}{*}{ Max } & \multicolumn{2}{|c|}{$\begin{array}{l}\text { Number of days over air quality standards } \\
\text { of } \mathrm{PM}_{2.5}(\%)\end{array}$} \\
\hline & & & & & & Japan $\left(35 \mu \mathrm{g} / \mathrm{m}^{3}\right)$ & WHO $\left(25 \mu \mathrm{g} / \mathrm{m}^{3}\right)$ \\
\hline $\mathrm{PM}_{2.5}\left(\mu \mathrm{g} / \mathrm{m}^{3}\right)$ & 2162 & $20.3(11.2)$ & 2.9 & 13.3 & 83.0 & $211(9.8)$ & $670(31.0)$ \\
\hline $\mathrm{NO}_{2}(\mathrm{ppb})$ & 2191 & $14.0(6.4)$ & 1.9 & 8.4 & 40.2 & & \\
\hline $0 x(p p b)^{*}$ & 2191 & 44.1 (15.5) & 2.7 & 19.8 & 77.0 & & \\
\hline $\mathrm{SO}_{2}(\mathrm{ppb})$ & 2191 & $3.5(1.6)$ & 0.7 & 2.0 & 12.8 & & \\
\hline Temperature $\left({ }^{\circ} \mathrm{C}\right)$ & 2191 & $17.4(7.9)$ & 0.7 & 13.8 & 31.8 & & \\
\hline Relative humidity (\%) & 2191 & $65.0(11.1)$ & 26.6 & 15.5 & 94.3 & & \\
\hline
\end{tabular}

*Daily maximum $8 \mathrm{~h}$ mean concentrations.

$\mathrm{NO}_{2}$, nitrogen dioxide; $\mathrm{Ox}$, photochemical oxidants; $\mathrm{PM}_{2.5}$, fine particulate matter; $\mathrm{SO}_{2}$, sulfur dioxide.

20-64 years and $45.4 \%$ for people aged 65 years or older; 86127 dispatches $(48.9 \%)$ were for men. A summary of meteorological factors and daily mean concentrations of air pollutants is shown in table 1 . The average $\mathrm{PM}_{2.5}$ concentration over the study period was $20.3 \mu \mathrm{g} / \mathrm{m}^{3}$, and concentrations exceeded Japanese air quality standards on 211 days (9.8\%).

Figure 1 shows the association between $\mathrm{PM}_{2.5}$ exposure and emergency ambulance dispatches. $\mathrm{PM}_{2.5}$ exposure was associated with increased ambulance dispatches for lag0-1 $\left(\mathrm{OR}=1.008\right.$ per $10 \mu \mathrm{g} / \mathrm{m}^{3}, 95 \%$ CI 1.002 to 1.014$)$. When the subjects transported to hospitals on national holidays were excluded, similar results were obtained $(\mathrm{OR}=1.008,95 \% \mathrm{CI}$ 1.002 to 1.014$)$. We restricted analyses to subjects exposed to $\mathrm{PM}_{2.5}$ concentrations below those stipulated by air quality standards. Although the point estimations changed slightly, those 95\% CIs showed considerable overlap (OR $=1.010(95 \%$ CI 1.001 to 1.019$)$ for $\leq 35 \mu \mathrm{g} / \mathrm{m}^{3}, \mathrm{OR}=1.007$ (0.994 to 1.020$)$ for $\left.\leq 25 \mu \mathrm{g} / \mathrm{m}^{3}\right)$. Including influenza epidemics in the model did not affect our results $(\mathrm{OR}=1.008,95 \%$ CI 1.002 to 1.014 ; see online supplementary table S2). In the two-pollutant models, the OR estimates for lag0-1 were similar (figure 1). The OR for lag0-1 was used to calculate the reduction in annual ambulance dispatches attributable to a $10 \mu \mathrm{g} / \mathrm{m}^{3}$ decrease in daily $\mathrm{PM}_{2.5}$ concentrations. The estimated reduction was approximately 260 (estimated range $=70-460$ ) dispatches in Fukuoka for 2012, with a correspondingly reduced administrative expenditure of approximately 2 million yen (c. \$20 000/€14 000).

Table 2 shows the results of cause-specific emergency ambulance dispatches according to age strata and sex. $\mathrm{PM}_{2.5}$ (lag0-1) was associated with an elevated risk of ambulance dispatches due to all causes in those aged 65 years or older $(\mathrm{OR}=1.012$ per $10 \mu \mathrm{g} / \mathrm{m}^{3}, 95 \%$ CI 1.003 to 1.021$)$ and in men (OR=1.011, 95\% CI 1.002 to 1.020$)$; however, no statistical evidence for interaction by age strata or sex was observed. In the causespecific analyses, the OR for respiratory diseases was 1.027 at lag0-1 (95\% CI 1.007 to 1.048$)$ in the overall analysis. We confirmed the robustness of this finding by adjusting for temperature at lag0-14 (see online supplementary table S3). In contrast, we did not find any associations for cardiovascular diseases.

Table 3 presents the associations between other air pollutant concentrations and emergency ambulance dispatches. Exposure to copollutants was not associated with ambulance dispatches due to all causes. However, positive associations were observed between $\mathrm{NO}_{2}$ and $\mathrm{SO}_{2}$ concentrations and respiratory diseases
Figure 1 ORs (black circles) of emergency ambulance dispatches per $10 \mu \mathrm{g} / \mathrm{m}^{3}$ increase in fine particulate matter $\left(\mathrm{PM}_{2.5}\right)$. Error bars indicate 95\% Cls.

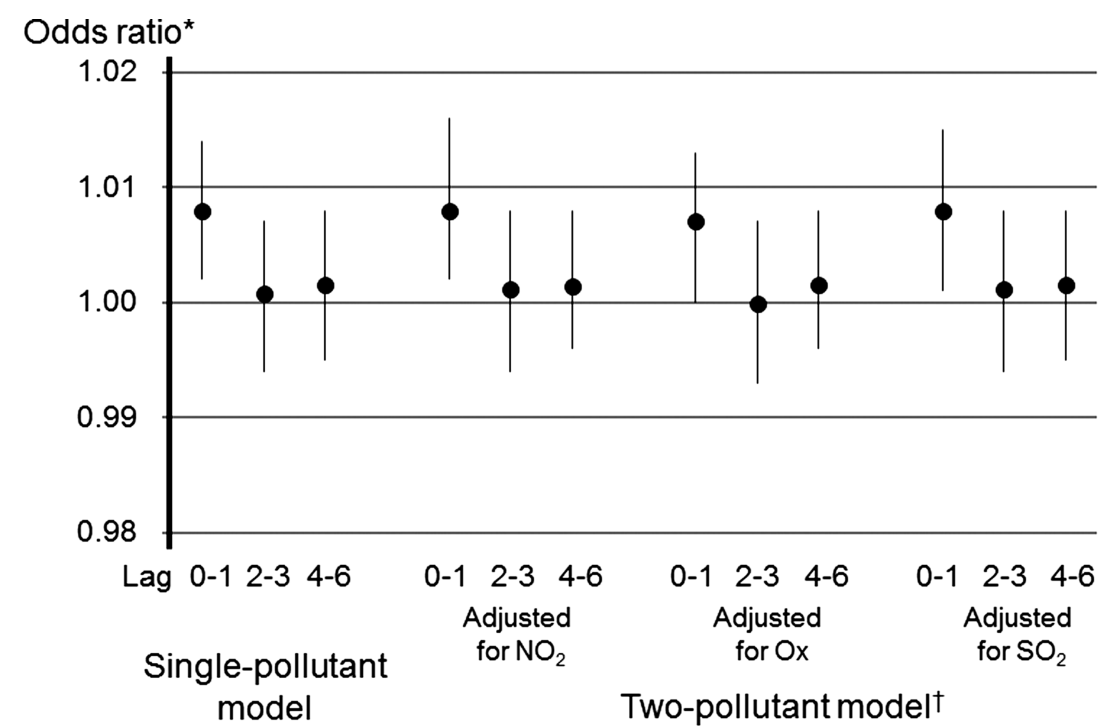

$\mathrm{NO}_{2}$, nitrogen dioxide; Ox, photochemical oxidants; $\mathrm{SO}_{2}$, sulfur dioxide.

*We entered the average concentrations of $\mathrm{PM}_{2.5}$ during lag0-lag1 (lag0-1), during lag2-lag3 (lag2-3) and during lag4-lag6 (lag4-6) simultaneously in the model, and also controlled for 4-day average ambient temperature and relative humidity.

tAdditionally adjusted for 4-day average concentrations of each air pollutant. 
Table 2 ORs and $95 \%$ Cls of cause-specific emergency ambulance dispatches per $10 \mu \mathrm{g} / \mathrm{m}^{3}$ increase in fine particulate matter (PM $\left.\mathrm{P}_{2.5}\right)$ by age strata and sex

\begin{tabular}{|c|c|c|c|c|c|c|c|c|c|c|c|c|}
\hline & \multicolumn{3}{|c|}{ All causes } & \multirow[b]{2}{*}{$p$ Value $^{\dagger}$} & \multicolumn{3}{|c|}{ Respiratory diseases } & \multirow[b]{2}{*}{ p Valuet } & \multicolumn{3}{|c|}{ Cardiovascular diseases } & \multirow[b]{2}{*}{$\mathrm{p}$ Valuet } \\
\hline & $\mathbf{n}$ & $\mathrm{OR}^{*}$ & $95 \% \mathrm{Cl}$ & & $\mathrm{n}$ & $\mathrm{OR}^{*}$ & $95 \% \mathrm{Cl}$ & & $\mathbf{n}$ & $\mathrm{OR}^{*}$ & $95 \% \mathrm{Cl}$ & \\
\hline \multicolumn{13}{|l|}{ Total } \\
\hline Lag0-1 & 176123 & 1.008 & 1.002 to 1.014 & & 15857 & 1.027 & 1.007 to 1.048 & & 31837 & 1.002 & 0.987 to 1.016 & \\
\hline Lag2-3 & & 1.001 & 0.994 to 1.007 & & & 1.003 & 0.982 to 1.025 & & & 0.998 & 0.983 to 1.013 & \\
\hline Lag4-6 & & 1.002 & 0.995 to 1.008 & & & 1.009 & 0.987 to 1.031 & & & 0.991 & 0.976 to 1.007 & \\
\hline \multicolumn{13}{|l|}{ Age (years) } \\
\hline \multicolumn{13}{|l|}{$<20$} \\
\hline Lag0-1 & 16415 & 1.011 & 0.991 to 1.031 & 0.59 & 1816 & 0.990 & 0.932 to 1.052 & 0.18 & 196 & 0.977 & 0.816 to 1.170 & 0.47 \\
\hline Lag2-3 & & 0.999 & 0.978 to 1.020 & & & 1.050 & 0.988 to 1.116 & & & 0.909 & 0.740 to 1.117 & \\
\hline Lag4-6 & & 0.991 & 0.969 to 1.013 & & & 0.977 & 0.913 to 1.046 & & & 0.914 & 0.750 to 1.115 & \\
\hline \multicolumn{13}{|l|}{$20-64$} \\
\hline Lag0-1 & 79734 & 1.004 & 0.995 to 1.013 & & 4325 & 0.993 & 0.955 to 1.032 & & 10001 & 0.998 & 0.973 to 1.023 & \\
\hline Lag2-3 & & 1.002 & 0.993 to 1.012 & & & 1.044 & 1.002 to 1.088 & & & 0.994 & 0.967 to 1.021 & \\
\hline Lag4-6 & & 1.006 & 0.997 to 1.016 & & & 1.015 & 0.973 to 1.060 & & & 0.990 & 0.962 to 1.018 & \\
\hline \multicolumn{13}{|l|}{$\geq 65$} \\
\hline Lag0-1 & 79974 & 1.012 & 1.003 to 1.021 & & 9716 & 1.048 & 1.022 to 1.076 & & 21640 & 1.004 & 0.986 to 1.021 & \\
\hline Lag2-3 & & 0.999 & 0.990 to 1.009 & & & 0.977 & 0.950 to 1.005 & & & 1.001 & 0.982 to 1.019 & \\
\hline Lag4-6 & & 0.999 & 0.989 to 1.009 & & & 1.010 & 0.982 to 1.040 & & & 0.992 & 0.974 to 1.012 & \\
\hline \multicolumn{13}{|l|}{ Sex } \\
\hline \multicolumn{13}{|l|}{ Men } \\
\hline Lag0-1 & 86127 & 1.011 & 1.002 to 1.020 & 0.63 & 8405 & 1.030 & 1.002 to 1.059 & 0.93 & 17116 & 1.006 & 0.987 to 1.026 & 0.26 \\
\hline Lag2-3 & & 1.001 & 0.992 to 1.010 & & & 1.006 & 0.977 to 1.037 & & & 1.011 & 0.991 to 1.033 & \\
\hline Lag4-6 & & 0.996 & 0.987 to 1.006 & & & 1.009 & 0.979 to 1.041 & & & 0.992 & 0.971 to 1.013 & \\
\hline \multicolumn{13}{|l|}{ Women } \\
\hline Lag0-1 & 89996 & 1.005 & 0.997 to 1.014 & & 7452 & 1.024 & 0.994 to 1.054 & & 14721 & 0.996 & 0.975 to 1.018 & \\
\hline Lag2-3 & & 1.001 & 0.992 to 1.010 & & & 1.000 & 0.969 to 1.032 & & & 0.982 & 0.961 to 1.005 & \\
\hline Lag4-6 & & 1.007 & 0.997 to 1.016 & & & 1.008 & 0.976 to 1.042 & & & 0.990 & 0.968 to 1.013 & \\
\hline
\end{tabular}

*We entered the average concentrations of $\mathrm{PM}_{2.5}$ during lag0-lag1 (lag0-1), during lag2-lag3 (lag2-3) and during lag4-lag6 (lag4-6) simultaneously in the model, and also controlled for 4-day average ambient temperature and relative humidity.

tStatistical interaction between $\mathrm{PM}_{2.5}$ and age strata and sex was tested by using a likelihood ratio test.

for lag2-3, with estimated ORs of 1.047 per $10 \mathrm{ppb}(95 \% \mathrm{CI}$ 1.005 to 1.091$)$ and 1.196 per $10 \mathrm{ppb}$ (95\% CI 1.001 to 1.429), respectively. With regard to $\mathrm{NO}_{2}$, the statistically significant association was found in those aged 19 years or younger $(\mathrm{OR}=1.162,95 \% \mathrm{CI} 1.028$ to 1.313$)$.

\section{DISCUSSION}

Observed association between short-term exposure to $\mathrm{PM}_{2.5}$ and emergency ambulance dispatches was robust to adjustment for copollutants and was independent of influenza epidemics. An estimated increase in ambulance dispatches of $0.8 \%$ per

Table 3 Associations of other air pollutants with emergency ambulance dispatches

\begin{tabular}{|c|c|c|c|c|c|c|}
\hline & \multicolumn{2}{|c|}{ All causes (n=176 123) } & \multicolumn{2}{|c|}{ Respiratory diseases ( $n=15857$ ) } & \multicolumn{2}{|c|}{$\begin{array}{l}\text { Cardiovascular diseases } \\
(\mathrm{n}=31837)\end{array}$} \\
\hline & $\mathrm{OR}^{*}$ & $95 \% \mathrm{Cl}$ & $\mathrm{OR}^{*}$ & $95 \% \mathrm{Cl}$ & $\mathrm{OR}^{*}$ & $95 \% \mathrm{Cl}$ \\
\hline \multicolumn{7}{|c|}{$\mathrm{NO}_{2}$ (per $10 \mathrm{ppb}$ ) } \\
\hline Lag0-1 & 1.005 & 0.993 to 1.017 & 1.032 & 0.993 to 1.072 & 0.989 & 0.963 to 1.016 \\
\hline Lag2-3 & 1.001 & 0.988 to 1.014 & 1.047 & 1.005 to 1.091 & 0.996 & 0.967 to 1.026 \\
\hline Lag4-6 & 1.005 & 0.992 to 1.019 & 0.996 & 0.953 to 1.040 & 0.991 & 0.961 to 1.022 \\
\hline \multicolumn{7}{|c|}{ Ox (per 10 ppb) } \\
\hline Lag0-1 & 1.005 & 0.999 to 1.011 & 1.011 & 0.991 to 1.030 & 1.004 & 0.990 to 1.018 \\
\hline Lag2-3 & 1.004 & 0.998 to 1.010 & 1.005 & 0.984 to 1.026 & 0.997 & 0.983 to 1.012 \\
\hline Lag4-6 & 0.998 & 0.992 to 1.004 & 1.009 & 0.988 to 1.030 & 0.994 & 0.979 to 1.008 \\
\hline \multicolumn{7}{|c|}{$\mathrm{SO}_{2}$ (per $10 \mathrm{ppb}$ ) } \\
\hline Lag0-1 & 1.026 & 0.973 to 1.081 & 1.095 & 0.924 to 1.297 & 1.001 & 0.886 to 1.132 \\
\hline Lag2-3 & 1.016 & 0.961 to 1.074 & 1.196 & 1.001 to 1.429 & 0.979 & 0.862 to 1.113 \\
\hline Lag4-6 & 1.035 & 0.976 to 1.097 & 1.035 & 0.855 to 1.253 & 1.028 & 0.898 to 1.177 \\
\hline
\end{tabular}


$10 \mu \mathrm{g} / \mathrm{m}^{3}$ rise in $\mathrm{PM}_{2.5}$ appeared to be similar to that reported in an earlier case-crossover analysis of all-cause mortality in Fukuoka City, ${ }^{9}$ though different outcomes made it difficult to directly compare our results with the earlier findings. We found no statistical evidence of interaction by age strata. A recent meta-analysis presented the higher particulate matter (aerodynamic diameter $\left.\leq 10 \mu \mathrm{m}\left(\mathrm{PM}_{10}\right)\right)$-associated mortality risk in people aged 65 years or older, ${ }^{24}$ so further research into agespecific differences is needed. In this meta-analysis, a $10 \mu \mathrm{g} / \mathrm{m}^{3}$ increase in $\mathrm{PM}_{10}$ exposure was associated with $0.28 \%$ (95\% CI 0.11 to 0.44 ) and $0.34 \%$ (95\% CI 0.19 to 0.49 ) increases in risk of death for men and women, respectively. ${ }^{24}$ The overlap of 95\% CIs means a less pronounced difference between men and women, suggesting consistency between our findings and the results of this meta-analysis.

As far as we know, this is the first study of the impact of exposure to $\mathrm{PM}_{2.5}$ on emergency ambulance dispatches. By our estimate, a $10 \mu \mathrm{g} / \mathrm{m}^{3}$ decrease in $\mathrm{PM}_{2.5}$ concentrations would have reduced the number of ambulance dispatches in Fukuoka by approximately 260 (estimated range $=70-460$ ) in 2012. As ambulance dispatches are not to be related to exposure to $\mathrm{PM}_{2.5}$ might remain in the all-cause dispatches, we should be cautious about possible overestimation. As our results show, the increased health risk of $\mathrm{PM}_{2.5}$ exposure is relatively small. However, since populations are aging rapidly all over the world, increasing vulnerability to $\mathrm{PM}_{2.5}$ exposure is expected. Japan has the longest life expectancy at birth worldwide, and the number of ambulance dispatches is estimated to exceed 6 million annually by 2023 or $2024 .^{13}$ From the viewpoint of public health, the sheer number of people subject to $\mathrm{PM}_{2.5}$ exposure means that even a small increased health risk is likely to have a financial impact on the emergency ambulance system. The estimated association between $\mathrm{PM}_{2.5}$ exposure and ambulance dispatches tended to be similar when analyses were restricted to subjects exposed to $\mathrm{PM}_{2.5}$ concentrations below those stipulated in Japanese air quality standards, so efforts should be made to reduce $\mathrm{PM}_{2.5}$ exposure as far as possible.

With respect to cause-specific emergency ambulance dispatches, we observed an association between short-term $\mathrm{PM}_{2.5}$ exposure and increased risk for respiratory diseases. This finding is biologically plausible, because the respiratory system is the first system affected by contact with $\mathrm{PM}_{2.5} ; \mathrm{PM}_{2.5}$ causes lung inflammation. ${ }^{1}$ Also, this does not contradict the results of past epidemiological studies. A study in Linz, Austria showed that exposure to $\mathrm{PM}_{2.5}$ tended to increase the risk of emergency ambulance dispatches for respiratory diseases at lag0 (per cent increase with a $10 \mu \mathrm{g} / \mathrm{m}^{3}$ increase $=2.1 \%, 95 \% \mathrm{CI}-2.1$ to 6.3$){ }^{6}$ In studies that used emergency department visits as a morbidity indicator, the point estimates for respiratory diseases were above unity, with or without statistical significance. ${ }^{25-30}$

In contrast with respiratory diseases, we did not observe any association between $\mathrm{PM}_{2.5}$ exposure and cardiovascular-related emergency ambulance dispatches, although $\mathrm{PM}_{2.5}$ exposure is strongly suspected to be a risk factor for cardiovascular diseases $^{1}$ : an increase risk of cardiovascular emergencies was shown in relation to $\mathrm{PM}_{2.5}$ exposure in Linz, Austria. ${ }^{6}$ However, not all studies report statistically significant associations between $\mathrm{PM}_{2.5}$ and cardiovascular disease-related mortality or morbidity probably because of demographic and geographic differences. ${ }^{31} 32$ The null association in our present study might be explained by difference in the pattern of cardiovascular diseases between Japan and Western countries: in Japan, the incidence of stroke is much higher than that of coronary heart disease, ${ }^{33}$ and while the association between $\mathrm{PM}_{2.5}$ and coronary heart disease has been documented, that between $\mathrm{PM}_{2.5}$ and stroke is still unclear. ${ }^{1}$ Further studies in terms of cardiovascular morbidity are required in Japan.

$\mathrm{NO}_{2}$ and $\mathrm{SO}_{2}$ exposure was positively associated in our study with emergency ambulance dispatches due to respiratory diseases. Observed associations were only for lag2-3, which might be explained by chance. However, exposure to $\mathrm{NO}_{2}$ and $\mathrm{SO}_{2}$ is known to be associated with respiratory symptoms, ${ }^{34}$ and $\mathrm{NO}_{2}$ exposure has the potential to adversely affect lung defence mechanisms against infection. ${ }^{35}$ In a recent panel study, shortterm exposure to $\mathrm{NO}_{2}$ was linked with airway inflammation and/or oxidative stress in healthy and asthmatic adolescents aged 14-19 years. ${ }^{36}$ Exposure to $\mathrm{SO}_{2}$ is known to decrease lung function and increase airway resistance and respiratory symptoms. ${ }^{34}$ Since ambient $\mathrm{SO}_{2}$ contributes to acid aerosol formation, the health effects of acid aerosols are also pertinent. ${ }^{34}$ Although the biological mechanisms by which $\mathrm{NO}_{2}$ and $\mathrm{SO}_{2}$ exert adverse effects on the respiratory system are not fully understood, our findings are unsurprising.

One strength of our study is that the data included all emergency ambulance dispatches in Fukuoka City, so any selection bias caused by not covering all of the target subjects was negligible. In addition, we analysed approximately 176000 cases, giving the study enough statistical power to detect even small effects of $\mathrm{PM}_{2.5}$ exposure and to estimate the precise effects of $\mathrm{PM}_{2.5}$ exposure on ambulance dispatch numbers. As a result, we were able to quantify the effect of $\mathrm{PM}_{2.5}$ exposure on ambulance dispatches regarding public health impact. The study also has some limitations, however. First, all data on $\mathrm{PM}_{2.5}$ concentrations came from a single monitoring station. While $\mathrm{PM}_{2.5}$ concentrations are known to be spatially homogeneous, ${ }^{37}$ exposure misclassification may have led to underestimation of the effects of $\mathrm{PM}_{2.5}$ on ambulance dispatches. Second, the cause-specific ambulance dispatches were classified on the basis of the initial diagnoses made by emergency physicians; these diagnoses might have changed later in some cases. However, a earlier study indicates no bias in the assignment of cardiopulmonary diagnoses related to daily air pollution concentrations in emergency departments. ${ }^{38}$ We think outcome misclassifications are likely to be non-differential, so we have no reason to suspect that using initial diagnoses affected the observed associations. Third, a possibility of residual confounding by influenza

\section{What is already known on this subject}

There is growing evidence, particularly in Europe and the USA, of an association between short-term exposure to fine particulate matter $\left(\mathrm{PM}_{2.5}\right)$ and mortality and morbidity.

\section{What this study adds}

- We showed that exposure to $\mathrm{PM}_{2.5}$ was associated with an increased number of emergency ambulance dispatches (as a proxy of acute health outcomes) in Fukuoka City, western Japan.

- To illustrate the public health impact, we estimated the extent to which a $10 \mu \mathrm{g} / \mathrm{m}^{3}$ decrease in $\mathrm{PM}_{2.5}$ concentrations would reduce the number of emergency ambulance dispatches. 
was left, because we did not obtain daily data on influenza incidence. A final limitation is that this study was performed in just one Japanese city, so further studies of other populations and locations are necessary to confirm the generalisability of our results.

In conclusion, by showing that exposure to $\mathrm{PM}_{2.5}$ was associated with emergency ambulance dispatches related to respiratory diseases, but not associated with cardiovascular-related dispatches, we have provided further evidence on the short-term health effects of $\mathrm{PM}_{2.5}$ exposure.

Contributors TM and KU specified the research question, and contributed to data collection, analysis, interpretation of results and drafting of the article. AT participated in analysis, interpretation of results and made critical revisions of the manuscript. MK and $\mathrm{HH}$ assisted with research design and contributed to data collection and critical revisions of the manuscript. TI assisted with research design, participated in interpretation of results and critical revisions of the manuscript. HN supervised the study and contributed to interpretation of results and critical revisions of the manuscript. All the authors approved the final version for submission.

Funding This study was supported by a Grant-in-Aid from the Ministry of Education, Culture, Sports, Science and Technology, Japan (25241015).

Competing interests None.

Provenance and peer review Not commissioned; externally peer reviewed.

\section{REFERENCES}

1 Anderson JO, Thundiyil JG, Stolbach A. Clearing the air: a review of the effects of particulate matter air pollution on human health. J Med Toxicol 2012;8:166-75.

2 Lim SS, Vos T, Flaxman AD, et al. A comparative risk assessment of burden of disease and injury attributable to 67 risk factors and risk factor clusters in 21 regions, 1990-2010: a systematic analysis for the Global Burden of Disease Study 2010. Lancet 2012;380:2224-60.

3 Bell ML, Ebisu K, Peng RD, et al. Hospital admissions and chemical composition of fine particle air pollution. Am J Respir Crit Care Med 2009;179:1115-20.

4 Kaneyasu N, Takami A, Sato K, et al. Long-range transport of $\mathrm{PM}_{2.5}$ in Northern Kyushu area in Spring. J Jpn Soc Atmos Environ 2010;45:227-34 (in Japanese with English abstract).

5 Yamagami M, Sagawa $T$, Nakato $Y$, et al. Analysis of $\mathrm{PM}_{2.5}$ air pollution episode in early February 2011 over Japan. J Jpn Soc Atmos Environ 2013;48:196-205 (in Japanese with English abstract).

6 Neuberger M, Moshammer H, Rabczenko D. Acute and subacute effects of urban air pollution on cardiopulmonary emergencies and mortality: time series studies in Austrian cities. Int J Environ Res Public Health 2013; 10:4728-51.

7 Straney L, Finn J, Dennekamp M, et al. Evaluating the impact of air pollution on the incidence of out-of-hospital cardiac arrest in the Perth Metropolitan Region: 2000-2010. J Epidemiol Community Health 2014;68:6-12.

8 Kaneyasu N, Takami A, Sato K, et al. Year-round behavior of $\mathrm{PM}_{2.5}$ in a remote island and urban sites in the northern Kyushu area, Japan. J Jpn Soc Atmos Environ 2011;46:111-18 (in Japanese with English abstract).

9 Ueda $\mathrm{K}$, Nitta $\mathrm{H}$, Ono $\mathrm{M}$, et al. Estimating mortality effects of fine particulate matter in Japan: a comparison of time-series and case-crossover analyses. J Air Waste Manag Assoc 2009:59:1212-18.

10 Zhu K, Zhang JF, Lioy PJ. Evaluation and comparison of continuous fine particulate matter monitors for measurement of ambient aerosols. J Air Waste Manag Assoc 2007; 57:1499-506

$11 \mathrm{Ng} \mathrm{CF}$, Ueda K, Takeuchi A, et al. Sociogeographic variation in the effects of heat and cold on daily mortality in Japan. J Epidemiol 2014;24:15-24.

12 Tanigawa K, Tanaka K. Emergency medical service systems in Japan: past, present, and future. Resuscitation 2006:69:365-70.
13 Hagihara A, Hasegawa M, Hinohara $Y$, et al. The aging population and future demand for emergency ambulances in Japan. Intern Emerg Med 2013;8:431-7.

14 Ueda K, Shimizu A, Nitta $H$, et al. Long-range transported Asian dust and emergency ambulance dispatches. Inhal Toxicol 2012;24:858-67.

15 Janes $H$, Sheppard L, Lumley T. Case-crossover analyses of air pollution exposure data: referent selection strategies and their implications for bias. Epidemiology 2005; 16:717-26.

16 Armstrong B. Models for the relationship between ambient temperature and daily mortality. Epidemiology 2006;17:624-31.

17 Japanese Ministry of the Environment. Environmental quality standards in JapanAir quality. http://www.env.go.jp/en/air/aq/aq.html (accessed 3 Feb 2014).

18 US Environmental Protection Agency. National ambient air quality standards. http:// www.epa.gov/air/criteria.html (accessed 3 Feb 2014).

19 World Health Organization. Air quality guidelines global update 2005. Geneva: WHO, 2005.

20 Hajat S, Haines A. Associations of cold temperatures with GP consultations for respiratory and cardiovascular disease amongst the elderly in London. Int $J$ Epidemiol 2002;31:825-30.

21 Rockhill B, Newman B, Weinberg C. Use and misuse of population attributable fractions. Am J Public Health 1998;88:15-19.

22 Fukuoka Fire Prevention Bureau. Fire-prevention annual report 2012 (in Japanese) http://119.city.fukuoka.Ig.jp/toukei/nenpou (accessed 3 Feb 2014).

23 Saitama Prefecture, Japan. Price tag of public administration (in Japanese). http:// www.pref.saitama.lg.jp/site/nefuda/sesaku.html (accessed 3 Feb 2014).

24 Bell ML, Zanobetti A, Dominici F. Evidence on vulnerability and susceptibility to health risks associated with short-term exposure to particulate matter: a systematic review and meta-analysis. Am J Epidemiol 2013;178:865-76.

25 Malig BJ, Green S, Basu R, et al. Coarse particles and respiratory emergency department visits in California. Am J Epidemiol 2013;178:58-69.

26 Winquist $A$, Klein $M$, Tolbert $P$, et al. Comparison of emergency department and hospital admissions data for air pollution time-series studies. Environ Health 2012;11:70.

27 Delfino RJ, Murphy-Moulton AM, Burnett RT, et al. Effects of air pollution on emergency room visits for respiratory illnesses in Montreal, Quebec. Am J Respir Crit Care Med 1997:155:568-76.

28 Peel JL, Tolbert PE, Klein M, et al. Ambient air pollution and respiratory emergency department visits. Epidemiology 2005;16:164-74.

29 Slaughter JC, Kim E, Sheppard L, et al. Association between particulate matter and emergency room visits, hospital admissions and mortality in Spokane, Washington. J Expo Anal Environ Epidemiol 2005;15:153-9.

30 Darrow LA, Klein M, Sarnat JA, et al. The use of alternative pollutant metrics in time-series studies of ambient air pollution and respiratory emergency department visits. J Expo Sci Environ Epidemiol 2011:21:10-19.

31 Brook RD, Rajagopalan S, Pope CA III, et al. Particulate matter air pollution and cardiovascular disease: An update to the scientific statement from the American Heart Association. Circulation 2010;121:2331-78.

32 Milojevic A, Wilkinson P, Armstrong B, et al. Short-term effects of air pollution on a range of cardiovascular events in England and Wales: case-crossover analysis of the MINAP database, hospital admissions and mortality. Heart 2014;100:1093-8.

33 Ueshima H, Sekikawa A, Miura K, et al. Cardiovascular disease and risk factors in Asia: a selected review. Circulation 2008:118:2702-9.

34 Bernstein JA, Alexis N, Barnes C, et al. Health effects of air pollution. J Allergy Clin Immunol 2004:114:1116-23.

35 Chauhan AJ, Johnston SL. Air pollution and infection in respiratory illness. Br Med Bull 2003:68:95-112.

36 Patel MM, Chillrud SN, Deepti KC, et al. Traffic-related air pollutants and exhaled markers of airway inflammation and oxidative stress in New York City adolescents. Environ Res 2013;121:71-8.

37 DeGaetano AT, Doherty OM. Temporal, spatial and meteorological variations in hourly $\mathrm{PM}_{2.5}$ concentration extremes in New York City. Atmos Environ 2004;38:1547-58.

38 Stieb DM, Beveridge RC, Rowe BH, et al. Assessing diagnostic classification in an emergency department: implications for daily time series studies of air pollution. Am J Epidemiol 1998;148:666-70. 